Published in final edited form as:

Cancer J. 2011 November ; 17(6): 405-415. doi:10.1097/PPO.0b013e318237e408.

\title{
Inherited Colorectal Cancer Syndromes
}

\author{
Fay Kastrinos, M.D., M.P.H. ${ }^{1,2}$ and Sapna Syngal, M.D., M.P.H. ${ }^{3,4,5}$ \\ ${ }^{1}$ Herbert Irving Comprehensive Cancer Center, Columbia University Medical Center, New York, \\ NY
}

${ }^{2}$ Division of Digestive and Liver Diseases, Columbia University Medical Center, New York, NY

${ }^{3}$ Division of Gastroenterology, Brigham and Women's Hospital, Boston, MA

${ }^{4}$ Population Sciences Division, Dana-Farber Cancer Institute, Boston, MA

${ }^{5}$ Harvard Medical School, Boston, MA

\begin{abstract}
Colorectal cancer is the most common gastrointestinal malignancy and the second leading cause of cancer death in both men and women in the United States. Most colorectal cancer cases diagnosed annually are due to sporadic events but up to 5\% are attributed to known monogenic disorders including Lynch syndrome, Familial Adenomatous Polyposis, $M Y H$-associated polyposis, and the rare hamartomatous polyposis syndromes. These inherited colorectal cancer syndromes confer a markedly increased risk for the development of multiple cancers and predictive genetic testing is available to identify mutation carriers and at-risk family members. Through personalized strategies for diagnosis and management, a substantial reduction in morbidity and mortality has been appreciated among patients at highest risk for the development of colorectal cancer.
\end{abstract}

Colorectal cancer (CRC) is a common malignancy, affecting over 141,000 new patients in the United States and estimated to cause over 49,000 deaths in the year 2011. ${ }^{1}$ Although the majority of patients with CRC have sporadic disease, up to $30 \%$ have a familial component and a potentially definable genetic basis. ${ }^{2,3}$ Over the last twenty years, highly penetrant monogenic germline mutations conferring high lifetime risk of CRC have been identified and account for 5-6\% of all CRC cases. ${ }^{4-6}$ These inherited CRC syndromes serve as a paradigm for personalized medicine based on available genomic information.

Readily identifying populations with an inherited predisposition to CRC is of great importance given the known benefit of tailored medical and surgical management. Through intensive endoscopic screening and prophylactic surgery, a substantial decreased in morbidity and mortality has been shown among patients at highest risk for CRC. ${ }^{7-9}$ Recognizing hereditary CRC syndromes also has an impact by allowing predictive genetic testing. Identifying gene mutation carriers improves the efficiency of cancer surveillance for affected individuals and helps distinguish between family members who require intense management versus those who can receive care appropriate for average-risk individuals.

Correspondence to: Sapna Syngal, MD, MPH Dana-Farber Cancer Institute 1 Jimmy Fund Way, SM 209 Boston, MA 02115 ssyngal@partners.org Phone: 617-632-6164, Fax: 617-632-4088.

Publisher's Disclaimer: This is a PDF file of an unedited manuscript that has been accepted for publication. As a service to our customers we are providing this early version of the manuscript. The manuscript will undergo copyediting, typesetting, and review of the resulting proof before it is published in its final citable form. Please note that during the production process errors may be discovered which could affect the content, and all legal disclaimers that apply to the journal pertain. 
Colorectal cancers caused by highly penetrant mutations, such as those involved in tumor suppression or the DNA mismatch repair system, include Lynch syndrome, Familial Adenomatous Polyposis, $\mathrm{MYH}$-associated polyposis and the rare hamartomatous polyposis syndromes. Key clinical features, the diagnostic evaluation, and management recommendations specific to each of these conditions are reviewed in this article.

\section{Lynch Syndrome}

Lynch syndrome accounts for 3-5\% of CRC cases and is caused by a germline mutation in one of four genes associated with the DNA mismatch repair (MMR) system: $M L H 1, M S H 2$, MSH6, or PMS2. ${ }^{4}$ In 1966, Dr. Henry Lynch and colleagues described an aggregation of colorectal and endometrial cancers inherited in an autosomal dominant manner in two large midwestern kindreds. ${ }^{10}$ Investigators have subsequently termed this inherited condition along with an expanded constellation of malignancies, and evidence of mismatch repair gene dysfunction, Lynch syndrome.

\section{Clinical Features}

Carriers of gene mutations in the MMR genes have a 50-80\% lifetime risk of developing CRC. ${ }^{14-6,11}$ Adenomatous polyps are the precursor lesions in the development of CRC and progression of the adenoma to carcinoma sequence in patients with Lynch syndrome is accelerated over a two to three year interval compared to the seven to ten year timeframe in sporadic CRC cases. CRC in Lynch syndrome has an early age of onset, with a mean age of 45 years, and multiple synchronous CRCs are not uncommon. The CRCs have a predilection for the proximal colon and have specific histologic features including poor differentiation, a mucinous component, and an intense Crohns-like lymphocytic reaction.

Patients with Lynch syndrome are also at an increased risk for a wide variety of extracolonic malignancies, most notably endometrial cancer. ${ }^{4-6,12,13}$ Among women, endometrial cancer is the second most common cancer associated with Lynch syndrome, with an estimated lifetime risk of 40 to $60 \% .{ }^{11}$ Sebaceous neoplasms of the skin are seen in the Lynch syndrome variant, Muir-Torre syndrome, and Turcot syndrome is associated with brain tumors, including glioblastomas and astrocytomas. The spectrum of Lynch syndromeassociated malignancies also includes cancers of the stomach, small intestine, pancreas, biliary tract, and urothelial carcinoma of the renal pelvis and ureter (Table 1).

\section{Genetics of Lynch Syndrome}

Alterations in the MMR system cause errors in DNA replication to accumulate and not be repaired, particularly in sequences of DNA known as microsatellites. Microsatellites are short mononucleotide or dinucleotide repeat sequences in which slippage of DNA can occur during replication resulting in either too few or many copies of microsatellite repeat sequences. An intact MMR system corrects these errors when they are not normally rectified by DNA polymerase. The MMR system requires cooperation of genes from the mutS (MSH2, MSH3, MSHO) and mutL (MLH1, MLH3, PMS1, and PMS2) families. ${ }^{14} \mathrm{~A}$ heterodimer complex between MSH2-MSH6 (MutS) recognizes single nucleotide mispairs and binds to the mismatched DNA sequence. A second heterodimer complex between MLH1-PMS2 (MutL) then binds to MutS to remove several bases from the newly synthesized DNA strand. This leads to resynthesis of DNA with the correct base pairing. At microsatellite sequences, insertion-deletion loops of one nucleotide are typically recognized by MSH2-MSH6, but larger insertion-deletion loops are recognized by the heterodimer $M S H 2-M S H 3$, followed by binding by MutL, excision, and resynthesis as described previously. ${ }^{14}$ The roles of $M L H 1-P M S 1$ and $M L H 1-M L H 3$ in human MMR function are not entirely clear at this time. For malignancy to occur in an individual with a germline MMR gene mutation, a second copy of the affected MMR gene must be somatically mutated and 
the altered microsatellites are found in the coding regions of genes involved in tumor initiation and progression.

\section{Diagnostic Evaluation}

Although germline genetic testing can identify mutation-positive individuals with Lynch syndrome, sequencing of the MMR genes is currently much too time-consuming, difficult, and expensive to be feasible for all CRC patients. Identification of candidates for testing has therefore relied on a number of different approaches which include assessment of personal and family cancer histories as well as molecular testing of CRC tumor specimens (Figure 1).

Clinical Criteria-It is imperative to obtain a comprehensive personal and family cancer history in evaluating one's risk for Lynch syndrome. Several classification systems were developed for the clinical diagnosis of Lynch Syndrome which rely solely on personal and family medical histories. The Amsterdam Criteria were developed in 1991 to define a subset of families with CRC for research purposes. These criteria require the following features (1) three or more CRC cases in which two of the affected individuals are first degree relatives of the third, (2) CRCs occurring in two generations, (3) one CRC occurring before age 50 years, and (4) exclusion of familial adenomatous polyposis. In families that meet Amsterdam criteria, the chance of identifying a germline mutation ranges from 4585\%. ${ }^{15-18}$ However, these criteria are too stringent as studies have shown that $40 \%$ of Lynch Syndrome families with an identified gene mutation did not meet Amsterdam criteria. Conversely, up to half of families that did meet Amsterdam criteria did not have a detectable MMR gene. ${ }^{19}$ The Bethesda Guidelines (updated to revised Bethesda Guidelines in 2004) were developed to improve the Amsterdam Criteria's sensitivity, include the extracolonic cancers associated with Lynch syndrome, and outline criteria that should lead to MSI tumor testing to aid in the identification of individuals with Lynch syndrome. ${ }^{20}$ However, in families that did not fulfill the Amsterdam criteria but met the revised Bethesda Criteria, a MMR gene mutation can be detected in only $15-30 \%$ of families. ${ }^{16-18}$ Given these limitations and the difficulty of implementing these clinical criteria by healthcare providers in routine practice, Lynch syndrome continues to be under-diagnosed and many at-risk individuals go without genetic evaluation and appropriate cancer preventive care. As a result, other approaches to select patients for clinical genetic testing have been favored and include universal molecular tumor testing in CRC patients and utilization of prediction model risk estimates.

Prediction Models-Several prediction models have recently been developed to facilitate the identification of patients and families with Lynch syndrome and to quantify the risk for carrying a germline MMR gene mutation. Studies validating the performance of these prediction models have shown them to all outperform both the Amsterdam and revised Bethesda criteria in predicting MMR gene mutation carriers ${ }^{21-23}$ and there is speculation that continued use of these prediction models may ultimately lead to them replacing the existing clinical criteria as prescreening tools for Lynch syndrome.

The current prediction models include but are not limited to MMRpro, MMRpredict, and the PREMM $_{1,2,6}$ model. ${ }^{24-26}$ The models differ in the methodology used to predict carrier status in addition to patient populations from which they were derived and validated. Studies to validate and compare the models' performance in identifying gene mutation carriers are needed among both clinic and population based cohorts in order to better promote their systematic use in clinical practice.

In a recent study evaluating the PREMM ${ }_{1,2,6}$ model's use in assessing cancer-free individuals for Lynch syndrome, a large simulated, population-based cohort was followed 
through life, considering various health risks including Lynch syndrome and its diagnosis and management. ${ }^{27}$ This study found that it is medically and cost effective to screen unaffected individuals between the ages of 25 and 35 years for Lynch syndrome using the PREMM $_{1,2,6}$ model and to proceed directly to clinical genetic testing in those subjects with a $5 \%$ or higher PREMM $M_{1,2,6}$ risk estimate. The ability to identify unaffected gene mutation carriers provides these high risk individuals with a means of primary cancer prevention through specialized screening programs.

Molecular Tumor Testing-Molecular diagnostic testing of CRC tumors is essential in the evaluation for Lynch syndrome. Testing all newly diagnosed CRC tumors for MSI or immunohistochemistry (IHC) for loss of MMR protein expression has been proposed as a strategy to screen CRC patients for Lynch syndrome. ${ }^{28}$ However, molecular tumor testing only identifies mutation carriers among those patients with a cancer diagnosis. It does not help individuals who have not yet been diagnosed with cancer but have a family history suggestive of Lynch syndrome.

Microsatellite Instability: The resultant MSI due to a defect in MMR is a hallmark of tumors associated with Lynch syndrome and is found in up to $90 \%$ of colorectal tumors of patients with germline MMR gene alterations. However, MSI can also be found in approximately $15 \%$ if sporadic CRC tumors which are due to somatic hypermethylation of the $M L H 1$ promoter region, as opposed to a germline defect as seen in Lynch syndrome. This decrease in specificity, which is magnified by increasing age at CRC diagnosis, makes MSI testing alone a less reliable approach in determining which patients with CRC should undergo clinical genetic testing. MSI testing is often used to complement those results obtained though IHC analyses.

Immunohistochemistry: Loss of expression of any of the MMR proteins associated with Lynch syndrome can be detected by IHC analysis of CRC tumors. IHC testing uses four antibodies specific for MLH1, MSH2, MSH6 and PMS2 proteins to evaluate CRC tumors for MMR deficiencies. IHC testing can therefore suggest which gene may be mutated in a given family and may direct gene-specific clinical genetic testing. Loss of expression of one of the four MMR proteins nearly always means that the CRC tumor will show MSI. However, normal IHC testing does not always exclude a microsatellite unstable tumor and this supports the complementary use of MSI with IHC results. While loss of $M S H 2$ protein expression in the tumor is highly specific for a germline mutation in this gene, the loss of $M L H 1$ expression is less specific and may be related to sporadic loss from hypermethylation in the $M L H 1$ gene promoter. To help differentiate between CRC associated with Lynch syndrome and sporadic cancer, $B R A F$ mutation testing may be used since the $B R A F$ mutation is frequently present in sporadic CRC with $M L H 1$ hypermethylation (Figure 1). Those tumors that show loss of $M L H 1$ expression but no BRAF mutation are often associated with Lynch syndrome.

In addition, there are pathogenic missense MSH6 gene mutations that do not completely abrogate protein expression yielding false negative results by IHC testing for MSH6 protein expression despite the presence of a germline mutation. These CRC tumors do not always display the MSI phenotype despite an inactive DNA MMR system related to an MSH6 gene mutation. ${ }^{29}$

Germline Mutation Analysis-Clinical genetic testing in CRC patients and at-risk family members with a suspected MMR gene mutation provides the opportunity to confirm the diagnosis of Lynch syndrome. Mutation analyses for germline mutations in the $M L H 1$, $M S H 2, M S H 6$, and PMS2 genes can be performed on DNA extracted from a peripheral 
blood sample. Testing includes full gene sequencing and southern blot analysis for the detection of large genomic deletions in these genes.

The most efficient approach in identifying a mutation carrier is to initiate the genetic evaluation in an individual affected with cancer. Mutation analysis is recommended in individuals with CRC whose tumors reveal abnormal IHC staining for MMR proteins or MSI. For individuals unaffected by cancer or when tumor specimens are unavailable for molecular testing, the prediction models can be used to estimate the risk of carrying a germline MMR gene mutation. For example, individuals whose family history produces a PREMM $_{1,2,6}$ model score of more than $15 \%$ should be offered risk counseling and considered for clinical genetic testing ${ }^{30}$ (Figure 1).

If a pathogenic mutation is detected in a cancer patient, the results are considered informative, and gene-specific, single-site mutation analysis can be offered to at-risk relatives. If genetic testing in a cancer patient does not reveal a mutation, the results are considered uninformative. In these cases, the personal and family history, along with molecular tumor testing results and the risk estimate determined through the prediction models, can help determine which individuals and family members may benefit from specialized cancer screening and surveillance.

Given the high cost of germline testing and the challenges related to the interpretation and communication of genetic testing results, the American Society for Clinical Oncology recommends that all genetic testing be performed along with genetic counseling which is available through most major cancer centers. ${ }^{31}$

\section{Special Considerations}

Familial Colorectal Cancer Syndrome X-Similar to Lynch syndrome, Familial Colorectal Cancer Syndrome X families have multiple cases of CRC with an apparent autosomal dominant pattern of inheritance but without a detected MMR gene mutation. ${ }^{32}$ In addition, CRC tumors in patients with Familial Colorectal Cancer Syndrome X do not have features of MSI and affected individuals do not appear to be at increased risk for extracolonic cancers.

EpCAM/TACSTD1 Mutations-Germline mutations in the epithelial cell adhesion molecule gene (EPCAM or TACSTD1) have recently been reported in a subset of families with Lynch syndrome and clinical genetic testing is available for the detection of this gene. These families displayed a similar phenotype to Lynch syndrome with early onset CRCs, as well as multiple extracolonic cancers, and have MSH2-deficient tumors. However MMR gene mutations were not identified through routine mutation analyses but rather, promoter hypermethylation of $M S H 2$ was detected in the tumors. Additional mutation analyses revealed germline deletions in the 3 ' region of the EPCAM/TACSTD1 gene which results in EpCAM-MSH2 fusion transcripts and the loss of protein expression related to $M S H 2$ on IHC testing. These deletions may account for up to $6 \%$ of Lynch syndrome cases, though additional studies are needed to validate this finding. ${ }^{33}$

\section{Management}

Specialized strategies for cancer prevention are recommended for individuals with Lynch syndrome given their high lifetime risk of colorectal and other extracolonic cancers, the young age of onset of colorectal neoplasia, and the accelerated adenoma to adenocarcinoma sequence (Table 2). 
Colorectal Cancer Screening-Individuals who are at risk for Lynch syndrome should have colonoscopies starting at age 20-25 years and every $1-2$ years thereafter. ${ }^{34,35}$ The accelerated progression from adenoma to carcinoma dictates the need for a shorter interval between examinations. Studies from European cohorts have shown that a three-year surveillance interval can decrease CRC mortality but a number of CRC can still arise during this time interval. ${ }^{7}$

Endometrial Cancer Screening-Endometrial cancer screening with annual transvaginal ultrasound and endometrial biopsies beginning at 30-35 years is recommended for women with MMR gene mutation carriers and those at risk for Lynch syndrome. This approach also provides screening for ovarian cancer. While data are lacking on the effectiveness of the currently recommended endometrial (or ovarian) cancer screening regimen, prophylactic hysterectomy and oophorectomy have been proven to be an effective way to reduce risks of gynecologic cancer. ${ }^{36}$

Screening for Other Cancers-Despite the myriad of extracolonic cancers associated with Lynch syndrome, there is currently insufficient evidence to definitively recommend screening for many of these malignancies. Options include urinary tract cancer screening via annual urine analysis and cytology, screening for gastric and duodenal cancer using upper endoscopy starting at 30-35 years and repeated every $2-3$ years $^{34}$, and annual dermatologic examinations to screen for cutaneous sebaceous neoplasms and identify patients with the Muir-Torre variant. Recommendations for screening are often tailored to the family history of these other cancers, and in some cases, the specific gene mutated.

Prophylactic Surgery-Prophylactic surgery may be considered as an alternative to annual CRC and endometrial cancer screening. The decision for prophylactic surgery depends in large part to the affected individual's ability to comply with surveillance examinations. In those mutation carriers who develop CRC, an extended surgical resection with a subtotal colectomy should be offered because of the high risk for developing metachronous lesions. In such cases, surveillance of the residual rectal mucosa can be accomplished by flexible sigmoidoscopy. Women with Lynch syndrome should be offered the option for prophylactic hysterectomy and oophorectomy once childbearing is completed as an effective method to reduce risks of endometrial and ovarian cancers. ${ }^{36}$

\section{Familial Adenomatous Polyposis}

FAP is the second most common inherited CRC syndrome and accounts for approximately $1 \%$ of all CRC cases. It is the most easily identified form of hereditary CRC, classically characterized by hundreds to thousands of adenomatous colorectal polyps that develop after the first decade of life. It is caused by a germline mutation in the adenomatous polyposis coli $(A P C)$ gene and is most often inherited in an autosomal dominant manner. However, up to $30 \%$ of cases can emerge as denovo gene mutations in the APC gene and consequently do not present with a family history of the disease.

\section{Clinical Features}

The hallmark of FAP is the development of hundreds to thousands of adenomas of the colon and rectum which confer a near $100 \%$ risk of CRC by age 40 years in the absence of any medical intervention. The age of onset of colonic adenomas is variable among gene mutation carriers: by age 10 approximately $15 \%$ of patients manifest adenomas, by age 20 the probability increases to $75 \%$, and by age $30,90 \%$ will have presented with FAP. ${ }^{37,38}$ Adenomatous polyps are usually discovered during endoscopic evaluation for symptoms such as gastrointestinal bleeding or during routine screening in individuals with a known family history of FAP. 
Upper gastrointestinal tract polyps, including duodenal and ampullary adenomas and gastric fundic gland polyps, are present in nearly $90 \%$ of FAP patients by the age of 70 years, with a median age of 38 years at diagnosis. ${ }^{39}$ The cumulative lifetime risk of duodenal cancer is approximately $4 \%$ and is the second cause of cancer death in FAP patients. ${ }^{40}$ Fundic gland polyps are the most common type of gastric polyp and have a low potential for malignant transformation.

A number of extraintestinal malignancies are associated with FAP and include papillary thyroid cancer, primary central nervous system tumors (medulloblastomas) associated with Turcot syndrome, and hepatoblastomas which may occur in children. A variant of FAP, Gardner Syndrome, is characterized by the association of polyposis with osteomas of the mandible and skull, epidermal cysts, supernumerary and/or impacted teeth, as well as desmoids tumors. Desmoid tumors are locally invasive fibromatoses that occur within the abdomen or abdominal wall and may develop following colectomy or other abdominal surgery. While desmoids do not have malignant potential, they are associated with high morbidity and mortality among affected FAP patients. Intraabdominal desmoids can cause bowel obstruction or perforation, ureteric obstruction, intestinal hemorrhage or enterocutanous fistula and treatment remains a challenge as surgical excision carries high recurrence rates of up to $45 \% .{ }^{41}$ Some patients with FAP also manifest a benign, asymptomatic ophthalmologic finding called congenital hypertrophy of the retinal pigment epithelium (CHRPE). Diagnosis of CHRPE, especially if there are multiple bilateral lesions, should prompt evaluation for FAP $^{42}$ (Table 1).

A subset of patients with APC mutations has a less obvious phenotype. Attenuated FAP (AFAP) is a phenotypically distinct variant of FAP where patients have 10 or more cumulative colorectal adenomas but often less than 100. Patients with AFAP have a predilection for developing polyps in the proximal colon with a fifteen year delay in CRC onset as compared to classic FAP. ${ }^{43}$

\section{Genetics of FAP}

The $A P C$ gene is a tumor suppressor gene and loss of its function in colonic epithelial cells initiates neoplastic transformation. Germline mutations in this gene are highly penetrant and cause the classic polyposis phenotype in the majority of mutation carriers. APC gene mutations are detected in more than $80 \%$ of patients with classic FAP. In AFAP, the mutation arises from $A P C$ mutations at the $5^{\prime}$ or $3^{\prime}$ ends of the gene or in certain areas of exon $9 .^{43,44}$

Recent reports indicate that up to $30 \%$ of individuals with classic polyposis but without a detectable $A P C$ mutation may have biallelic mutations in the $M Y H$ gene, a base excision repair gene (see following section on $M Y H$-associated polyposis). ${ }^{45}$ Patients with $M Y H$ associated polyposis can present with a similar phenotype to classic or attenuated FAP, but with an autosomal recessive pattern of inheritance, thereby making the diagnosis more challenging.

\section{Diagnostic Evaluation}

Germline Mutation Analysis-Genetic testing and counseling is the standard of care for individuals with classic FAP and at-risk family members in order to provide risk stratification (Figure 2). Genetic evaluation begins with the affected individual with the polyposis phenotype and includes full gene sequencing and southern blot analysis for an $A P C$ gene mutation. This testing identifies $A P C$ gene mutations in up to $80 \%$ of patients with classic FAP but only 10-30\% of AFAP cases. If a mutation is not detected, testing for biallelic mutations in the $M Y H$ gene should be considered. ${ }^{46-49}$ Patients with classic 
polyposis but without an identified genetic mutation are considered to have indeterminate test results. Their family members must be considered at-risk for developing FAP and should undergo cancer screening as described below.

\section{Management}

Screening for CRC—For known APC gene mutation carriers or at-risk individuals, colorectal screening for polyps should begin with flexible sigmoidoscopy at the age of 1012 years with annual colonoscopy once polyps are detected. Once the polyp burden is too numerous to be managed endoscopically, prophylactic colectomy is recommended. Total proctocolectomy with ileoanal pouch anastomosis is the preferred approach over lessextensive surgeries, such as total colectomy with ileorectal anastomosis. If there is any remaining rectal mucosa, annual endoscopic surveillance is needed as the remnant is at risk for neoplastic transformation. In AFAP, colonoscopy should be initiated in early adulthood and surveillance should be performed every 1-2 years (Table 2). Approximately $33 \%$ of patients with AFAP can be managed with annual colonoscopy and polypectomy in the longterm and do not require colectomy; the remaining patients ultimately proceed to colectomy which can often be performed with an ileorectal anastomosis, as the polyp load in the rectum can be managed endoscopically. ${ }^{34,50}$

Screening for duodenal and ampullary lesions-Upper gastrointestinal endoscopy is recommended to evaluate for adenomas in the duodenum and ampulla. This should be initiated at age 25-30 years in patients with FAP and AFAP and performed every 1-3 years depending on the polyp burden. ${ }^{51}$ Upper endoscopy with a side-viewing endoscope is needed to visualize the ampulla and obtain biopsies. Duodenal polyp biopsies, polypectomy, and/or ablative endoscopic techniques are performed depending on polyp size, multiplicity, and location. Ampullary adenomas may be resected endoscopically depending on size and/ or degree of dysplasia; for advanced histologic lesions and those lesions not amenable to therapeutic endoscopy, surgical resection may be necessary. Over $20 \%$ of patients will require endoscopic or surgical management of duodenal or ampullary adenomas. ${ }^{34}$

Screening for other cancers-Given the increased risk for thyroid cancer, there is expert consensus that simple thyroid palpation during annual physical examination and/or annual thyroid ultrasonography be performed. ${ }^{52}$ As hepatoblastomas may occur in children, hepatic ultrasonography and serum AFP tests are recommended annually for screening during the first five years of life. There is currently no evidence to support routine screening for other cancers.

Chemoprevention-Chemoprevention for adenomatous polyp formation has been proposed but is not a reasonable alternative to surgery. Sulindac, a nonsteroidal antiinflammatory medication, has been shown to cause regression of colorectal adenomas in FAP patients by inducing apoptosis but long-term benefits have been inconsistent and studies have shown incomplete polyp regression. ${ }^{53} \mathrm{COX}-2$ inhibitors have been proven to decrease duodenal adenoma burden and reduce colorectal polyp formation with high-dose treatment. ${ }^{54}$ However, concerns over cardiovascular and thrombotic events in recent adenoma chemoprevention trials have made use of these agents less accepted.

\section{MYH-associated Polyposis}

Inherited mutations in the recently described human analogue of the Escherichia coli muty gene, $M Y H$, have been shown to predispose individuals to multiple colorectal adenomas and carcinoma. Patients with $M Y H$-associated polyposis (MAP) typically present with clinical features similar to AFAP but in the absence of a strong multigenerational family history of polyposis given its autosomal recessive mode of inheritance (Table 1). 


\section{Clinical Features}

There is phenotypic heterogeneity among patients with MAP and the estimated risk of CRC is as high as $80 \%$ for biallelic $\mathrm{MYH}$ mutation carriers. ${ }^{55}$ Patients typically present between ages 40 to 60 years with a variable number of colorectal adenomatous polyps. ${ }^{56}$ There are limited reports on the prevalence of extracolonic tumors associated with MAP. In one study, gastric and duodenal polyps were noted in $11 \%$ and $17 \%$ of patients respectively and the estimated risk of duodenal cancer was $4 \%$, comparable to that in FAP. ${ }^{57}$

The risk of developing CRC in monoallelic $M Y H$ gene mutation carriers has been variable. In a meta-analysis examining the contribution of monoallelic $M Y H$ carriers on CRC risk, the pooled estimated odds ratio has been reported to be $1.26 .^{58}$

\section{Genetics of $M Y H$-associated Polyposis}

$M Y H$ is a base excision repair (BER) gene located on chromosome 1p35 involved in repairing DNA that is damaged by reactive oxygen species generated during aerobic metabolism and by exogenous stimuli such as various chemical oxidants and ionizing radiation. Loss of $M Y H$ activity leads to an unusually high frequency of $\mathrm{G}: \mathrm{C}$ to $\mathrm{T}: \mathrm{A}$ transversions resulting in nonsense or splicesite mutations in the $A P C$ gene. ${ }^{59}$ This suggests faulty repair of 7,8-dihydro-8-oxo-2'deoxyguanosine (8-oxoG), one of the most deleterious products of oxidative DNA damage, which readily mispairs with adenine residues leading to transversion mutations in the daughter strand. When intact, $M Y H$ glycosylase scans the daughter strand after replication and removes the mispaired nucleoside.

\section{Diagnostic Evaluation}

Germline Mutation Analysis-Appropriate candidates for $M Y H$ mutation analysis testing include individuals who (a) exhibit features of classic or attenuated FAP and (b) have a family history of adenomas or CRC compatible with a recessive pattern of inheritance (Figure 2). In addition, $M Y H$ testing may be considered in patients with a young onset CRC diagnosis whose tumors do not exhibit defective DNA MMR as biallelic $M Y H$ mutations have been found in individuals with early onset CRC and few to no polyps. ${ }^{60,61}$

Genetic testing for $M Y H$ mutations is first performed by mutation specific testing for two of the most common mutations found in individuals of western European ancestry, Y165C and G382D. Together, these mutations account for approximately $85 \%$ of MAP cases. ${ }^{62}$ If one of these mutations is present, then sequencing is done to identify an inactivating mutation on the opposite allele; if both alleles are mutated to inactivate the gene, CRC risk is near $80 \%$. If neither of the two most common mutations is found and a MAP etiology is strongly suspected, or if a person is not of western European ancestry, then primary sequencing is done to detect other less common mutations. Screening for $A P C$ and $M Y H$ gene mutations may be performed in parallel in some patients, such as those with isolated cased of multiple adenomas.

Genetic testing should also be recommended to siblings of biallelic mutation carriers as they carry the highest risk (25\%) of carrying biallelic mutations. Genetic testing in the partners of patients with biallelic $M Y H$ mutations should be consider since a biallelic carrier may produce affected children if the partner is a monoallelic $M Y H$ mutation carrier. ${ }^{63}$ In such cases the disease will appear to be inherited in an autosomal dominant manner.

\section{Management}

Biallelic mutation carriers should be managed similarly to those persons with classic FAP. ${ }^{64-66}$ However, most data support a later age of polyposis onset than that seen in FAP and colonoscopy is therefore recommended starting at 25 years with surveillance every $1-2$ 
years. Colectomy should be considered if the colorectal polyp burden makes endoscopic surveillance improbable. Endoscopic screening of the upper gastrointestinal tract is also recommended to start at age 30 years and should be performed every 1-3 years depending on polyp burden (Table 2). Given the slight increase in adenoma and CRC likelihood in monoallelic $M Y H$ mutation carriers, baseline colonoscopy is suggested at age 25 years and intense lifetime surveillance should be pursued if colorectal adenomas are noted. In the absence of adenomatous polyps on initial colonoscopy, repeat screening is recommended every $3-5$ years. ${ }^{66}$

\section{HAMARTOMATOUS POLYPOSIS SYNDROMES}

Intestinal hamartomatous polyps are associated with the inherited conditions: Peutz-Jeghers syndrome, juvenile polyposis, and Cowden syndrome. While these disorders are rare with incidences too low to be precisely determined, they are associated with a sizeable risk of gastrointestinal malignancy.

\section{Peutz-Jeghers Syndrome}

Peutz-Jeghers syndrome (PJS) is characterized by multiple hamartomatous polyps of the small bowel. The lifetime risk of any gastrointestinal cancer is near 70\%, with CRC risk estimated at 39\%. Additional malignancies, including breast and sex cord cancers, increase an affected individual's lifetime risk of cancer to near $90 \%$. Other high cancer risks associated with PJS are pancreatic cancer, with a lifetime risk estimated to be $36 \% .67,68$

\section{Clinical Features}

Individuals with PJS develop hamartomatous polyps throughout their gastrointestinal tract with up to $30 \%$ of patients having gastric and colonic hamartomas as well as those most often found in the small intestine (jejunum). The most characteristic extraintestinal manifestation of PJS is mucocutanous pigmentation, usually of the lips and buccal mucosa, which presents in childhood. Patients will typically present in young adulthood with gastrointestinal bleeding or abdominal pain related to small bowel obstruction or intussusception. A clinical diagnosis of PJS can be made in individuals who have at least two of the following features: (1) hyperpigmentation of lips buccal mucosa, (2) $\geq 2$ hamartomatous polyps in the small bowel, or (3) a family history of PJS $^{34}$ (Table 1, Figure 2).

\section{Genetics of PJS}

PJS is an autosomal dominant disorder due to a germline mutation in STK-11, a serine/ threonine kinase gene with tumor suppressor function. Up to $70 \%$ of individuals with a clinical diagnosis of PJS are found to carry the STK-11 gene and ongoing research is aimed at identifying other genes that may be involved in PJS.

\section{Management}

Patients with PJS require careful endoscopic surveillance for removal of polyps and screening for extraintestinal cancers ${ }^{69}$ (Table 2). Recommendations include upper endoscopy and small bowel imaging (with small bowel series or capsule endoscopy) starting at age 8 years. ${ }^{70}$ Endoscopic removal of all polyps greater than 1.5 centimeters or those causing symptoms is recommended which may require double-balloon enteroscopy or intraoperative enteroscopy. Surveillance should be conducted every 2-3 years depending on polyp burden. Baseline colonoscopy should be performed at age 18 years and every 2-3 years thereafter. Affected women should have annual mammography or breast MRI starting at age 25 years. Screening for sex cord tumors includes annual testicular examination or testicular ultrasound scans from ages 10 years for boys and pelvic examination, transvaginal 
ultrasound and Papanicolaou smear beginning at age 18 years for women. Ongoing studies are evaluating pancreatic cancer screening with endoscopic ultrasound and/or imaging with MRI or CT every 1-2 years in affected individuals, starting at age 30 years. ${ }^{68}$

\section{Juvenile Polyposis}

Juvenile polyposis is characterized by the appearance of multiple juvenile polyps throughout the gastrointestinal tract and carries a $40 \%$ lifetime risk of CRC. These individuals are also at increased risk for gastric and small bowel cancers which may appear at young ages.

\section{Clinical Features}

Affected individuals typically have multiple juvenile polyps and a family history of gastrointestinal cancer. Most often, patients present during childhood with gastrointestinal bleeding, abdominal pain, or anemia. Juvenile polyposis should be suspected in an individual with (1) $\geq$ three juvenile polyps of the colon, (2) multiple gastric or small bowel juvenile polyps, or (3) family history of juvenile polyps and any number of juvenile polyps (Figure 2).$^{34}$ Polyps may be few to more than 100 over a lifetime. In addition, a subset of patients may also have hemorrhagic or mucocutaneous telangiectasias, cardiopulmonary abnormalities and other congenital anomalies (Table 1).

\section{Genetics of Juvenile Polyposis}

Juvenile polyposis is an autosomal dominant condition with germline mutations in the SMAD4 and BMPRla genes. Only $40 \%$ of affected individuals with a clinical diagnosis of juvenile polyposis carry an associated gene mutation, and therefore clinical genetic testing is often uninformative.

\section{Management}

Patients with a known gene mutation, and those at risk given a family history of juvenile polyposis should undergo upper gastrointestinal and colorectal screening for hamartomatous polyps starting at age 18 years. ${ }^{70}$ In there are no polyps, repeat endoscopies should be performed in 2-3 years (Table 2). If hamartomatous polyps are found, affected individuals should have frequent upper endoscopy and colonoscopy for removal of polyps and every year thereafter. In some cases colectomy and/or gastrectomy may be indicated for increased polyp burden.

\section{Cowden Syndrome}

Cowden Syndrome is an autosomal dominant condition most often recognized clinically by gastrointestinal hamartomatous polyps and various skin lesions. There are a number of cancers associated with Cowden syndrome, including breast, thyroid, endometrial and skin cancer. However, the rarity of the condition makes it difficult to ascertain specific risks that are different from those in the general population. Presently, the relation between Cowden syndrome and CRC remains unclear. In a series of patients with Cowden syndrome, many had multiple colon polyps with a wide pathologic spectrum, both benign and malignant. ${ }^{71,72}$

\section{Clinical findings}

Benign skin manifestations are common and include facial trichilemmomas, verrucous skin lesions of the face and limbs, and cobblestone-like hyperkeratotic papules of the gingiva and buccal mucosa. On endoscopy multiple hamartomatous polyps are found in the gastrointestinal tract in addition to diffuse macroscopic esophageal acanthosis. Patients may also have macrocephaly (Table 1, Figure 2). 


\section{Genetics of Cowden syndrome}

Cowden syndrome is associated with germline mutations in the PTEN gene. However, the exact role of germline PTEN mutations in the carcinogenesis of CRC remains unclear.

\section{Management}

Although screening for a number of extraintestinal cancers is required, many cases of Cowden syndrome are undiagnosed or diagnosis comes at a late stage, partly due to the variable phenotype of the disease. There are currently no accepted guidelines regarding endoscopic screening for any gastrointestinal cancers, but recent recommendations include colonoscopy starting at age 35 years with surveillance every 3-5 years depending on the polyp findings. Recommendations continue to evolve as patients with Cowden syndrome have a mixed polyp phenotype. ${ }^{71}$ Annual MRI screening of the breasts is recommended in women with Cowden syndrome starting at age 30-35 years or five years earlier than the earliest breast cancer diagnosis in the family. Thyroid ultrasound is recommended in young adulthood, with surveillance based on findings or thyroid palpation during annual examination. Surveillance for endometrial cancer with transvaginal ultrasound and biopsies is recommended to begin at age 35 years and annually thereafter.

\section{Acknowledgments}

Grant Support: NCI K24 113433 (SS) and NCI K07 151769 (FK)

\section{REFERENCES}

1. Siegel R, Ward E, Brawley O, et al. Cancer statistics, 2011: The impact of eliminating socioeconomic and racial disparities on premature cancer deaths. CA Cancer J Clin. 2011; 61:212236. [PubMed: 21685461]

2. Burt RW. Colon cancer screening. Gastroenterology. 2000; 119:837-853. [PubMed: 10982778]

3. Lichtenstein P, Holm NV, Verkasalo PK, et al. Environmental and heritable factors in the causation of cancer. N Engl J Med. 2000; 343:78-85. [PubMed: 10891514]

4. Lynch HT, de la Chapelle A. Hereditary colorectal cancer. N Engl J Med. 2003; 348:919-932. [PubMed: 12621137]

5. Grady WM. Genetic testing for high-risk colon cancer patients. Gastroenterology. 2003; 124:15741594. [PubMed: 12761718]

6. Chung DC, Rustgi AK. The hereditary nonpolyposis colorectal cancer syndrome: genetic and clinical implications. Ann Intern Med. 2003; 138:560-570. [PubMed: 12667026]

7. Jarvinen HJ, Aarnio M, Mustonen H, et al. Controlled 15-year trial on screening for colorectal cancer in families with hereditary nonpolyposis colorectal cancer. Gastroenterology. 2000; 118:829-834. [PubMed: 10784581]

8. de Jong AE, Hendiks YM, Kleibeuker JH, et al. Decrease in mortality in Lynch syndrome families because of surveillance. Gastroenterology. 2006; 130:665-671. [PubMed: 16530507]

9. Heiskanen I, Luostarinen T, Jarvinen HJ. Impact of screening examinations on survival in familial adenomatous polyposis. Scand J Gastroenterol. 2000; 35:1284-1287. [PubMed: 11199368]

10. Lynch HT, Shaw MW, Magnuson CW, et al. Hereditary factors in cancer: Study of two large midwestern kindreds. Arch Intern Med. 1966; 117:106-112.

11. Stoffel E, Mukherjee B, Raymond VM, et al. Calculation of risk of colorectal and endometrial cancer among patients with Lynch Syndrome. Gastroenterology. 2009; 137:1621-1627. [PubMed: 19622357]

12. Aarnio M, Mecklin JP, Aaltonen LA, et al. Life-time risk of different cancers in hereditary nonpolyposis colorectal cancer (HNPCC) syndrome. Int J Cancer. 1995; 64:430-433. [PubMed: 8550246]

13. Kastrinos F, Mukherjee B, Tayob N, et al. Risk of pancreatic cancer in Lynch Syndrome. JAMA. 2009; 302:1790-1795. [PubMed: 19861671] 
14. Grady WM, Carethers JM. Genomic and epigenetic instability in colorectal cancer pathogenesis. Gastroenterology. 2008; 135:1079-1099. [PubMed: 18773902]

15. Nyström-Lahti M, Wu Y, Moisio AL, et al. DNA mismatch repair gene mutations in 55 kindreds with verified or putative hereditary nonpolyposis colorectal cancer. Hum Mol Genet. 1996; 5:763769. [PubMed: 8776590]

16. Moslein G, Tester DJ, Lindor NM, et al. Microsatellite instability and mutation analysis of hMSH2 and hMLH1 in patients with sporadic, familial and hereditary colorectal cancer. Hum Mol Genet. 1996; 5:1245-1252. [PubMed: 8872463]

17. Wijnen J, Khan PM, Vasen H, et al. Hereditary nonpolyposis colorectal cancer families not complying with the Amsterdam criteria show extremely low frequency of mismatch-repair-gene mutations. Am J Hum Genet. 1997; 61:329-335. [PubMed: 9311737]

18. Lynch HT, de la Chapelle A. Genetic susceptibility to non-polyposis colorectal cancer. J Med Genet. 1999; 36:801-818. [PubMed: 10544223]

19. Lindor NM, McMaster ML, Lindor CJ, et al. Concise handbook of familial cancer susceptibility syndromes: second edition. J Natl Cancer Inst Monogr. 2008; 308:1-93. [PubMed: 18559331]

20. Umar A, Boland CR, Terdiman JP, et al. Revised Bethesda Guidelines for hereditary Nonpolyposis colorectal cancer (Lynch Syndrome) and microsatellite instability. J Natl Cancer Inst. 2004; 96:261-268. [PubMed: 14970275]

21. Green RC, Parfrey PS, Woods MO, et al. Prediction of Lynch Syndrome in Consecutive Patients with Colorectal Cancer. J Natl Cancer Inst. 2009; 101:331-340. [PubMed: 19244167]

22. Pouchet CJ, Wong N, Chong G, et al. A comparison of models used to predict MLH1, MSH2 and MSH6 mutation carriers. Ann Oncol. 2009; 20:681-688. [PubMed: 19164453]

23. Monzon JG, Cremin C, Armstrong L, et al. Validation of predictive models for germline mutations in DNA mismatch repair genes in colorectal cancer. Int J Cancer. 2010; 126:930-939. [PubMed: 19653273]

24. Barnetson RA, Tenesa A, Farrington SM, et al. Identification and survival of carriers of mutations in DNA mismatch repair genes in colon cancers. N Engl J Med. 2006; 354:2751-2763. [PubMed: 16807412]

25. Chen S, Wang W, Lee S, et al. Prediction of germline mutations and cancer risk in the Lynch syndrome. JAMA. 2006; 296:1479-1487. [PubMed: 17003396]

26. Kastrinos F, Steyerberg E, Mercado R, et al. The PREMM1,2,6 Model predicts risk of germline MLH1, MSH2, and MSH6 germline mutations based on cancer history. Gastroenterology. 2011; 140:73-81. [PubMed: 20727894]

27. Dinh TA, Rosner BI, Atwood JC, et al. Health Benefits and Cost-Effectiveness of Primary Genetic Screening for Lynch Syndrome in the General Population. Cancer Prev Res. 2011; 4:9-22.

28. Hampel H, Frankel WL, Martin E, et al. Feasibility of screening for Lynch syndrome among patients with colorectal cancer. J Clin Oncol. 2008; 26:5783-5788. [PubMed: 18809606]

29. Wu Y, Berends MJ, Mensink RG, et al. Association of hereditary nonpolyposis colorectal cancerrelated tumors displaying low microsatellite instability with MSH6 germline mutations. Am J Hum Genet. 1999; 65:1291-1298. [PubMed: 10521294]

30. Kastrinos F, Steyerberg EW, Balmaña J, et al. Comparison of the clinical prediction model PREMM $_{1,2,6}$ with colorectal cancer molecular tumor testing for Lynch Syndrome in the Colon Cancer Family Registry. Gastroenterology. 2010; 138:A1028.

31. American Society for Clinical Oncology Policy statement update: genetic testing for cancer susceptibility. J Clin Oncol. 2003; 21:2397-2406. [PubMed: 12692171]

32. Lindor NM, Rabe K, Petersen GM, et al. Lower cancer incidence in Amsterdam-I criteria families without mismatch repair deficiency: familial colorectal cancer type X. JAMA. 2005; 293:19791985. [PubMed: 15855431]

33. Kempers MJ, Kuiper RP, Ockeleon CW, et al. Risk of colorectal and endometrial cancers in EPCAM deletion-positive Lynch syndrome: a cohort study. Lancet Oncol. 2011; 12:49-55. [PubMed: 21145788]

34. Jasperson KW, Tuohy TM, Neklason DW, et al. Hereditary and Familial Colon Cancer. Gastroenterology. 2010; 138:2044-2058. [PubMed: 20420945] 
35. Lindor NM, Petersen GM, Hadley DW, et al. Recommendations for the care of individuals with an inherited predisposition to Lynch syndrome: a systematic review. JAMA. 2006; 296:1507-1517. [PubMed: 17003399]

36. Schmeler KM, Lynch HT, Chen LM, et al. Prophylactic surgery to reduce the risk of gynecological cancers in Lynch syndrome. New Engl Med. 2006; 354:261-169.

37. Petersen GM, Slack J, Nakamura. Screening guidelines and premorbid diagnosis of familial adenomatous polyposis. Gastroenterology. 1991; 1000:1658-1671. [PubMed: 1673441]

38. Galiatsatos P, Foulkes WD. Familial Adenomatous Polyposis. Am J Gastroenterol. 2006; 101:385398. [PubMed: 16454848]

39. Bulow S, Bjork J, Christensen IJ, et al. Duodenal adenomatosis in familial adenomatous polyposis. The DAF Study Group. Gut. 2004; 53:381-386. [PubMed: 14960520]

40. Vasen HFA, Bulow S, Myrhoj T, et al. Decision analysis in the management of duodenal adenomatosis in familial adenomatous polyposis. Gut. 1997; 40:716-719. [PubMed: 9245923]

41. Heiskanen I, Jarvinen HJ. Occurrence of desmoids tumours in familial adenomatous polyposis and results of treatment. Int J Colorect Dis. 1996; 11:157-162.

42. Traboulsi EI, Krush AJ, Gardner EJ, et al. Prevalence and importance of pigmented ocular fundus lesions in Gardner's syndrome. N Engl J Med. 1987; 316:661-667. [PubMed: 3821797]

43. Knudsen AL, Bisgaard ML, Burlow S. Attenuated familial adenomatous polyposis (AFAP). A review of the literature. Fam Cancer. 2003; 2:43-55. [PubMed: 14574166]

44. Burt, RW.; Jacoby, RF. Polyposis Syndromes. Textbook of Gastroenterology. 4thed.. Vol. Volume 2. Lippincott Williams \& Wilkins; New York: 2003. p. 1914-1939.

45. Fleischmann C, Peto J, Chradle J, et al. Comprehensive analysis of the contribution of germline MYH variation to early-onset colorectal cancer. Int J Cancer. 2004; 118:554-558. [PubMed: 14991577]

46. Renkonen ET, Nieminen P, Abdel-Rahman WM, et al. Adenomatous Polyposis Families That Screen APC Mutation-Negative by Conventional Methods Are Genetically Heterogeneous. J Clin Oncol. 2005:5651-5659. [PubMed: 16110024]

47. Armstrong JG, Davies DR, Guy SP, et al. APC mutations in familial adenomatous polyposis families in the Northwest of England. Hum Mutat. 1997; 10:376-380. [PubMed: 9375853]

48. Russell AM, Zhang J, Luz J, et al. Prevalence of MYH germline mutations in Swiss APC mutation-negative polyposis patients. Int J Cancer. 2006; 118:1937-1940. [PubMed: 16287072]

49. Aretz S, Uhlhaas S, Goergens H, et al. MUTYH-associated polyposis: 70 of 71 patients with biallelic mutations present with attenuated or atypical phenotype. Int J Cancer. 2006; 119:807814. [PubMed: 16557584]

50. Burt RW, Leppert MF, Slattery ML, et al. Genetic testing and phenotype in a large kindred with attenuated familial adenomatous polyposis. Gastroenterology. 2004; 127:444-451. [PubMed: 15300576]

51. Gallagher MC, Phillips RK, Bulow S. Surveillance and management of upper gastrointestinal disease in familial adenomatous polyposis. Fam Cancer. 2006; 5:263-273. [PubMed: 16998672]

52. Herraiz M, Barbesino G, Faquin W, et al. Prevalence of thyroid cancer in familial adenomatous polyposis syndrome and the role of screening ultrasound examination. Clin Gastoenterol Hepatol. 2007; 5:367-373.

53. Giardiello FM, Hamilton SR, Krush AJ, et al. Treatment of colonic and rectal adenomas with sulindac in familial adenomatous polyposis. N Engl J Med. 1993; 328:131-6. [PubMed: 8416424]

54. Phillips RK, Wallace MH, Lynch PM, et al. A randomized, double blind, placebo controlled study of celecoxib, a selective cyclooxygenase 2 inhibitor, on duodenal polyposis on familial adenomatous polyposis. Gut. 2001; 50:857-60. [PubMed: 12010890]

55. Jenkins MA, Croitoru ME, Monga N, et al. Risk of Colorectal Cancer in Monoallelic and Biallelic Carriers of MYH Mutations: A Population-Based Case-Family Study. Cancer Epidemiol Biomarkers Prev. 2006; 15:312-314. [PubMed: 16492921]

56. Doxey BW, Kuwada SK, Burt RW. Inherited polyposis syndromes: Molecular mechanisms, clinicopathology, and genetic testing. Clin Gastroenterol Hepatol. 2005; 3:633-641. [PubMed: 16206494] 
57. Vogt S, Jones N, Christian D, et al. Expanded extracolonic tumor spectrum in MutYH-associated polyposis. Gastroenterology. 2009; 137:197-1985.

58. Webb EL, Rudd MF, Houlston RS. Colorectal cancer risk in monoallelic carriers of MYH variants. Am J Hum Genet. 2006; 79:768-771. [PubMed: 16960817]

59. Al-Tassan N, Chmiel NH, Maynard J, et al. Inherited variants of MYH associated with G:C->T:A mutations in colorectal tumors. Nat Genet. 2002:227-232. [PubMed: 11818965]

60. Wang L, Baudhuin LM, Boardman LA, et al. MYH mutations in patients with attenuated and classical polyposis and with young-onset colorectal cancer without polyps. Gastroenterology. 2004; 127:9-16. [PubMed: 15236166]

61. Jo WS, Bandipalliam P, Shannon KM, et al. Correlation of polyp number and family history of colon cancer with germline MYH mutations. Clin Gastroenterol Hepatol. 2008; 10:1022-1028.

62. Jones S, Emmerson P, Maynaard J, et al. Biallelic germline mutations in MYH predispose to multiple colorectal adenoma and somatic G:C-< T:A mutations. Hum Mol Genet. 2002; 11:29612967. [PubMed: 12393807]

63. Kastrinos F, Syngal S. Recently identified colon cancer predispositions: MYH and MSH6 mutations. Semin Oncol. 2007; 34:418-424. [PubMed: 17920897]

64. Lubbe SJ, DiBernardo MC, Chandler IP, et al. Clinical implications of the colorectal cancer risk associated with MUTYH mutation. J Clin Oncol. 2009; 27:3975-3980. [PubMed: 19620482]

65. Sieber O, Lipton L, Crabtree M, et al. Multiple colorectal adenomas, classic adenomatous polyposis, and germline mutations in MYH. N Engl J Med. 2004; 348:791-799. [PubMed: 12606733]

66. Wagner A, Hendriks YMC, Meijers-Heijboer EJ, et al. Atypical HNPCC owing to MSH6 germline mutations: analysis of a large Dutch pedigree. J Med Genet. 2001; 38:318-322. [PubMed: 11333868]

67. Giardiello FM, Trimbath JD. Peutz-Jeghers syndrome and management recommendations. Clin Gastroenterol Hepatol. 2006; 4:408-415. [PubMed: 16616343]

68. Van Lier MGF, Wagner A, Mathus-Vliegen MD, et al. High cancer risk in Peutz-Jeghers syndrome: a systematic review and surveillance recommendations. Am J Gastroenterol. 2010; 105:158-164.

69. Wirtzfeld DA, Petrelli NJ, Rodriguez-Bigas MA. Hamartomatous polyposis syndromes: molecular genetics, neoplastic risk, and surveillance recommendations. Ann Surg Oncol. 2001; 8:319-327. [PubMed: 11352305]

70. National Comprehensive Cancer Network (NCCN). Clinical Practice Guidelines in oncology: colorectal cancer screening. Available at: http://www.nccn.org.

71. Stanich PP, Owens VL, Sweetser S, et al. Colonic polyposis and neoplasia in Cowden syndrome. Mayo Clin Proc. 2011; 86:489-492. [PubMed: 21628613]

72. Heald B, Mester J, Rybicki L, et al. Frequent gastrointestinal polyps and colorectal adenocarcinomas in a prospective series of PTEN mutation carriers. Gastroenterology. 2010; 139:1927-1933. [PubMed: 20600018] 


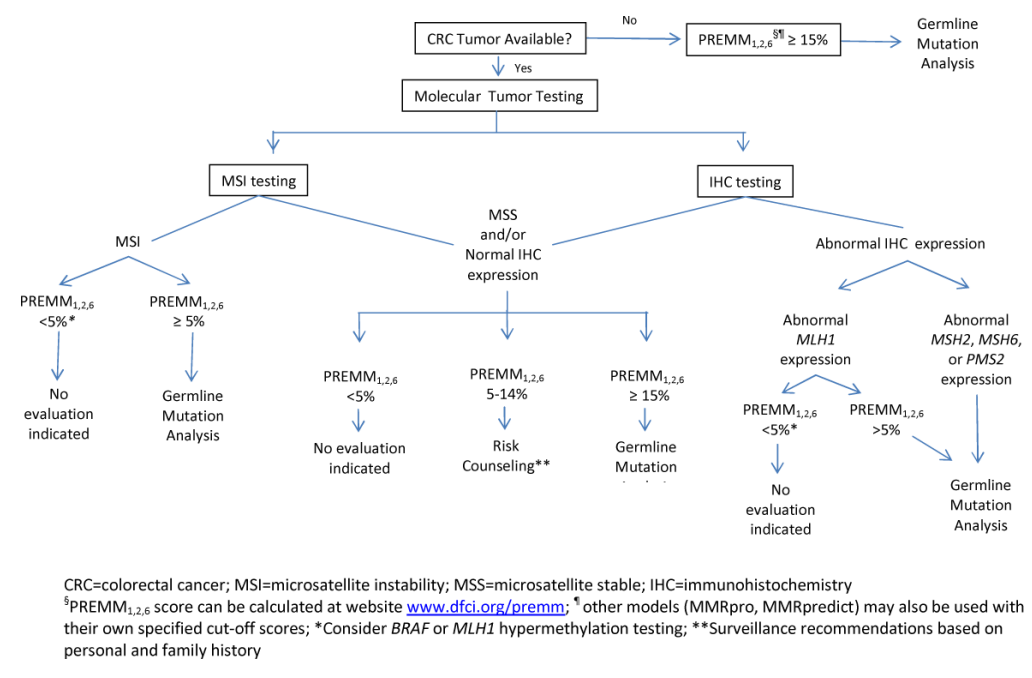

FIGURE 1.

Evaluation for genetic predisposition in patients with nonpolyposis CRC. MSI indicates microsatellite instability; MSS, microsatellite stable. ${ }^{\S} \mathrm{PREMM}_{1,2,6}$ score can be calculated at the following Web site: www.dfci.org/premm; other models (MMRpro, MMRpredict) may also be used with their own specified cutoff scores. *Consider BRAF or MLHI hypermethylation testing. **Surveillance recommendations based on personal and family history. 


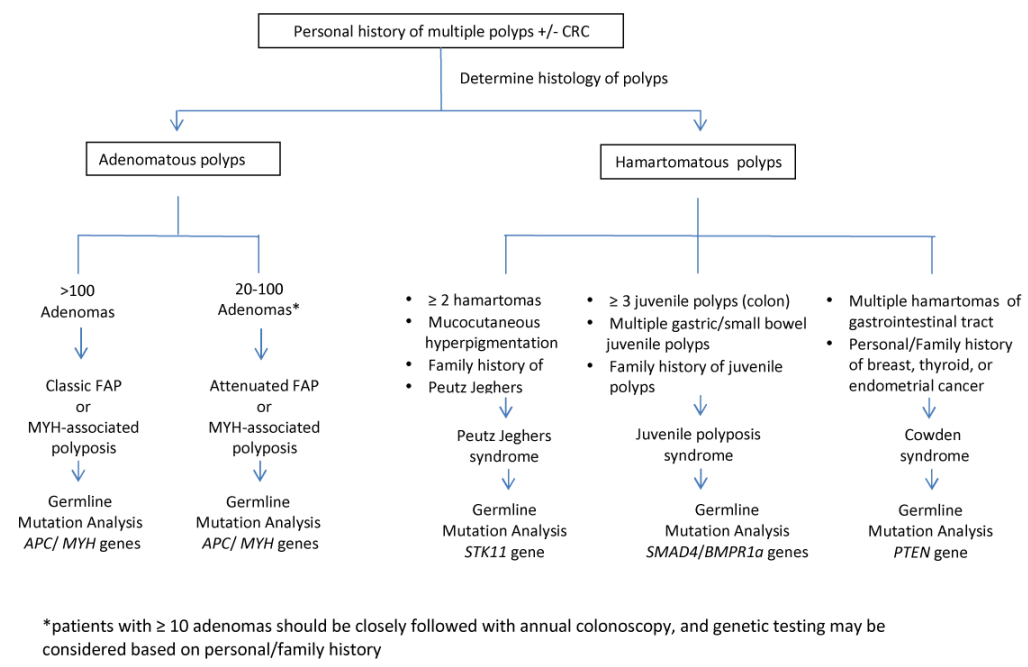

FIGURE 2.

Evaluation for genetic predisposition in patients with CRC and/or polyps. *Patients with 10 or more adenomas should be closely followed up with annual colonoscopy, and genetic testing may be considered based on personal/family history. 
Table 1

Clinical features associated with inherited colorectal cancer syndromes

\begin{tabular}{|c|c|c|}
\hline Inherited Syndrome & Affected Gene(s) & Clinical Features \\
\hline Lynch syndrome & $\begin{array}{l}\text { MLH1, MSH2, } \\
\text { MSH6, PMS2, } \\
\text { TACSTD1/EPCAM }\end{array}$ & $\begin{array}{cl}\text { Gastrointestinal } \\
\text { - } & \text { Young onset colorectal cancer (<50 years) } \\
\text { - } & \text { Proximal }>\text { distal colon cancers } \\
\text { - } & \text { Synchronous colorectal cancers common } \\
\text { - } & \text { Colorectal cancer tumors demonstrate microsatellite instability } \\
\text { - } & \text { Other cancers: stomach, small bowel, pancreatic, biliary tract } \\
\text { Other } & \\
\text { - Non-gastrointestinal cancers: endometrial, ovarian, upper urinary } \\
\\
\text { - } \quad \begin{array}{l}\text { tract, central nervous system (glioblastoma, astrocytoma) } \\
\text { Sebaceous adenomas }\end{array}\end{array}$ \\
\hline $\begin{array}{l}\text { Familial adenomatous polyposis } \\
\text { (FAP) }\end{array}$ & $A P C$ & $\begin{aligned} & \text { Gastrointestinal } \\
& \text { - }>100 \text { colorectal adenomas appearing by second decade of life } \\
& \text { - } \text { Gastric fundic gland polyps } \\
& \text { - } \text { Duodenal and ampullary adenomas/ adenocarcinomas } \\
& \text { Other } \\
& \text { - } \begin{array}{l}\text { Non-gastrointestinal cancers: thyroid, hepatoblastoma, central } \\
\text { nervous system (medulloblastoma) }\end{array} \\
& \text { - } \text { CHRPE } \\
& \text { - } \text { Epidermoid cysts } \\
& \text { - } \text { Osteomas jaw and skull } \\
& \text { - } \text { Desmoid tumors } \\
& \text { Supernumerary/impacted teeth }\end{aligned}$ \\
\hline $\begin{array}{l}\text { Attenuated familial adenomatous } \\
\text { polyposis (AFAP) }\end{array}$ & $A P C$ & $\begin{array}{l}\text { Gastrointestinal } \\
\text { - } \quad<100 \text { colorectal adenomas appearing by third decade of life } \\
\text { - Duodenal and ampullary adenomas/Adenocarcinomas }\end{array}$ \\
\hline MYH-associated polyposis & MYH & $\begin{array}{l}\text { Gastrointestinal } \\
\text { - } \quad<100 \text { colorectal adenomas appearing by third decade of life } \\
\text { - } \quad \text { Duodenal adenomas/adenocarcinoma }\end{array}$ \\
\hline Peutz-Jeghers syndrome (PJS) & STK11 & $\begin{array}{l}\text { Gastrointestinal } \\
\text { - Hamartomatous polyps in gastrointestinal tract (most prevalent in } \\
\text { small bowel) } \\
\text { - Other cancers: pancreas, stomach, small bowel }\end{array}$ \\
\hline & & Other \\
\hline
\end{tabular}




\begin{tabular}{|c|c|c|}
\hline Inherited Syndrome & Affected Gene(s) & Clinical Features \\
\hline & & $\begin{array}{l}\text { Non-gastrointestinal cancers: breast, ovary, lung, endometrial } \\
\text { cervical, testicular }\end{array}$ \\
\hline \multirow[t]{6}{*}{ Juvenile polyposis } & SMAD4 BMPR1A & Gastrointestinal \\
\hline & & - $\quad \geq$ juvenile polyps in gastrointestinal tract \\
\hline & & - Other cancers: pancreas, stomach, small bowel \\
\hline & & Other \\
\hline & & - Mucocutaneous telangiectasias \\
\hline & & - Congenital cardiopulmonary defects \\
\hline \multirow[t]{7}{*}{ Cowden syndrome } & PTEN & \multirow{3}{*}{$\begin{array}{l}\text { Gastrointestinal } \\
\text { - Hamartomatous polyps in gastrointestinal tract } \\
\text { - } \quad \text { Glycogenic acanthosis of the esophagus }\end{array}$} \\
\hline & & \\
\hline & & \\
\hline & & Other \\
\hline & & - $\quad$ Macrocephaly \\
\hline & & - $\quad$ Skin lesions: i.e. oral and skin papillomas,trichilemmomas \\
\hline & & - $\quad$ Non-gastrointestinal cancers: breast, thyroid \\
\hline
\end{tabular}


Table 2

Lifetime cancer risks and management recommendations for inherited colorectal cancer syndromes

\begin{tabular}{|c|c|c|c|c|}
\hline Condition & Lifetime cancer risk & & Screening recommendations & Initiation age \\
\hline \multirow[t]{9}{*}{ Lynch syndrome } & Colorectum & $60-80 \%$ & Colonoscopy: every $1-2$ y & $20-25$ y \\
\hline & Endometrium & $40-60 \%$ & Transvaginal ultrasound \pm endometrial & $30 \mathrm{y}$ \\
\hline & Ovarian & $9-12 \%$ & $\begin{array}{l}\text { biopsy: annually; consider prophylactic } \\
\text { TAH/BSO when childbearing complete }\end{array}$ & \\
\hline & Stomach & $11-19 \%$ & EGD: every $2-3$ years & $30-35$ y \\
\hline & Upper urinary tract & $4-5 \%$ & Urinalysis \pm cytology: annually & $30-35$ y \\
\hline & Pancreas & $3-4 \%$ & \multirow{4}{*}{$\begin{array}{l}\text { There is currently no evidence to support } \\
\text { screening for other Lynch syndrome } \\
\text { related cancers }\end{array}$} & \\
\hline & Biliary tract & $2-7 \%$ & & \\
\hline & Small bowel & $1-4 \%$ & & \\
\hline & Central nervous system ${ }^{*}$ & $1-3 \%$ & & \\
\hline \multirow[t]{8}{*}{$\begin{array}{l}\text { Familial adenomatous polyposis } \\
\text { (FAP) }\end{array}$} & \multirow[t]{3}{*}{ Colorectum } & \multirow[t]{3}{*}{$100 \%$} & $\begin{array}{l}\text { Flexible sigmoidoscopy; Annual } \\
\text { colonoscopy when polyps detected }\end{array}$ & \multirow[t]{3}{*}{$10-12$ y } \\
\hline & & & $\begin{array}{l}\text { Prophylactic colectomy when polyp burden } \\
\text { not amenable to endoscopic resection }\end{array}$ & \\
\hline & & & $\begin{array}{l}\text { Following colectomy: screen annually if } \\
\text { remaining rectum or ileal pouch }\end{array}$ & \\
\hline & Duodenum/ampulla & $4-12 \%$ & EGD: every $1-3$ years & \multirow[t]{2}{*}{$20-25$ y } \\
\hline & Thyroid & $1-2 \%$ & $\begin{array}{l}\text { Annual thyroid palpation } \pm \\
\text { ultrasonography }\end{array}$ & \\
\hline & Hepatoblastoma & $1-2 \%$ & $\begin{array}{l}\text { Annual hepatic ultrasonography and AFP } \\
\text { for the first five years of life }\end{array}$ & \multirow[t]{3}{*}{6 months } \\
\hline & Central nervous system ${ }^{* *}$ & $<1 \%$ & $\begin{array}{l}\text { There is currently no evidence to support } \\
\text { screening for other related cancers }\end{array}$ & \\
\hline & Stomach & $<1 \%$ & & \\
\hline \multirow{5}{*}{$\begin{array}{l}\text { Attenuated familial adenomatous } \\
\text { polyposis (AFAP) }\end{array}$} & \multirow[t]{3}{*}{ Colorectum } & \multirow[t]{3}{*}{$70 \%$} & Colonoscopy: every $1-3$ years & \multirow[t]{3}{*}{$20-25$ y } \\
\hline & & & $\begin{array}{l}\text { Prophylactic colectomy when polyp burden } \\
\text { not amenable to endoscopic resection }\end{array}$ & \\
\hline & & & $\begin{array}{l}\text { Following colectomy: screen annually if } \\
\text { remaining rectum or ileal pouch }\end{array}$ & \\
\hline & Duodenum/ampulla & $4-12 \%$ & EGD every $1-3$ years & $20-25$ y \\
\hline & Thyroid & $1-2 \%$ & $\begin{array}{l}\text { Annual thyroid palpation } \pm \\
\text { ultrasonography }\end{array}$ & \\
\hline \multirow[t]{4}{*}{ MYH-associated polyposis (MAP) } & \multirow[t]{3}{*}{ Colorectum } & \multirow[t]{3}{*}{$80 \%$} & Colonoscopy: every $1-2$ years & \multirow[t]{3}{*}{$25 \mathrm{y}$} \\
\hline & & & $\begin{array}{l}\text { Prophylactic colectomy when polyp burden } \\
\text { not amenable to endoscopic resection }\end{array}$ & \\
\hline & & & $\begin{array}{l}\text { Following colectomy: screen annually if } \\
\text { remaining rectum or ileal pouch }\end{array}$ & \\
\hline & Duodenum & $4 \%$ & EGD every $1-3$ years & $30 \mathrm{y}$ \\
\hline \multirow[t]{4}{*}{ Peutz-Jeghers syndrome (PJS) } & Colorectum & $39 \%$ & Colonoscopy: every $2-3$ years & 18 y \\
\hline & Breast & $55 \%$ & Mammography or breast MRI: annually & $25 \mathrm{y}$ \\
\hline & Pancreas & $36 \%$ & $\begin{array}{l}\text { Endoscopic ultrasound or MRCP every 1- } \\
2 \text { years }\end{array}$ & $30 \mathrm{y}$ \\
\hline & Stomach & $29 \%$ & EGD: every $2-3$ years & $8 \mathrm{y}$ \\
\hline
\end{tabular}




\begin{tabular}{|c|c|c|c|c|}
\hline \multirow[t]{2}{*}{ Condition } & \multicolumn{2}{|l|}{ Lifetime cancer risk } & \multirow{2}{*}{$\begin{array}{l}\text { Screening recommendations } \\
\text { No current recommendations }\end{array}$} & \multirow[t]{2}{*}{ Initiation age } \\
\hline & Lung & $15 \%$ & & \\
\hline & Small bowel & $13 \%$ & $\begin{array}{l}\text { Small bowel imaging (capsule endoscopy, } \\
\text { small bowel follow-through, CT or MRI } \\
\text { enteroscopy): every } 2-3 \text { years }\end{array}$ & $8 \mathrm{y}$ \\
\hline & Endometrium/cervix & $9 \%$ & $\begin{array}{l}\text { Annual pelvic examination, Papanicolaou } \\
\text { smear, and transvaginal ultrasound }\end{array}$ & $18 \mathrm{y}$ \\
\hline & Ovarian & $21 \%$ & & \\
\hline & Testicle & $<1 \%$ & $\begin{array}{l}\text { Annual testicular examination } \pm \\
\text { ultrasonography }\end{array}$ & $10 \mathrm{y}$ \\
\hline \multirow[t]{3}{*}{ Juvenile polyposis } & Colorectum & $40-50 \%$ & Colonoscopy: every $2-3$ years & 18 y \\
\hline & Stomach & $20 \%$ & $\begin{array}{l}\text { EGD: annually when polyps are found } \\
\text { otherwise every } 2-3 \text { years }\end{array}$ & 18 y \\
\hline & Small intestine & $<1 \%$ & $\begin{array}{l}\text { There is currently no evidence to support } \\
\text { screening }\end{array}$ & \\
\hline \multirow[t]{3}{*}{ Cowden syndrome } & Breast & $50 \%$ & Annual mammography or breast MRI & $30-35$ y \\
\hline & Thyroid & $10 \%$ & Annual thyroid ultrasonography & $18 \mathrm{y}$ \\
\hline & Colorectum & $16 \%$ & Colonoscopy every $3-5$ years & $35 \mathrm{y}$ \\
\hline
\end{tabular}

$\mathrm{TAH} / \mathrm{BSO}=$ total abdominal hysterectomy/bilateral salpingo-oophorectomy;

EGD=esophagoduodenoscopy; $\mathrm{MRI}=$ magnetic resonance imaging; $\mathrm{MRCP}=$ magnetic resonance cholangiopancreatography; $\mathrm{CT}=$ computed tomography.

* Central nervous system tumors in Lynch syndrome include glioblastoma and astrocytomas

*** Central nervous system tumors in FAP include medulloblastoma 